\title{
RESENHA
}

\section{VALENTIN VOLÓCHINOV - A PALAVRA NA VIDA E A PALAVRA NA POESIA}

\author{
Janaina Souza Silva iD 1
}

A resenha tem como referência bibliográfica a seguinte obra:

VOLÓCHINOV, Valentin. A palavra na vida e a palavra na poesia: ensaios, artigos, resenhas e poemas. Organização, tradução, ensaio introdutório e notas: Sheila Grillo e Ekaterina Vólkova Américo. São Paulo: Editora 34, 2019, 400 páginas.

\begin{abstract}
"Todo fenômeno pode ser melhor (sic) compreendido se observado no processo de seu surgimento e desenvolvimento." (p. 238).

"A língua tornou-se material da criação literária." (p. 236).

"Se não compreendermos a essência da língua e da linguagem, se não compreendemos seu papel na vida social, jamais saberemos abordar corretamente aquilo que chamamos de estilística do discurso literário, isto é, a técnica da construção do objeto literário, que deve ser dominada, sem exceção, por todos os escritores desejosos de se tornar mestres em sua arte, e não amadores e diletantes superficiais." (p. 238).
\end{abstract}

Esta é uma valiosa obra de um dos intelectuais mais conhecidos do Círculo Bakhtiniano, Valentin Nikoláiev Volóchinov (1895-1936). Trata-se de uma coletânea de textos inéditos e já conhecidos do autor (ensaios, artigos, resenhas e poemas), elaborada pelas pesquisadoras Sheila Grillo e Ekaterina Vólkova Américo, entre os meses de maio e junho do ano de 2016, utilizando dos arquivos do Instituto de História Comparada das Literaturas e Línguas do Ocidente e do Oriente (ILIAZV), em São Petersburgo, Rússia.

Volóchinov não é um autor desconhecido aos leitores e pesquisadores que se debruçam sobre o Círculo de Bakhtin ${ }^{2}$, de forma que seu trabalho sempre esteve ora associado às polêmicas de autoria, ora à sombra dos trabalhos de Bakhtin, do qual se tornou amigo desde a sua mocidade. No entanto, no que concerne à pertinência da investigação para a atualidade, de acordo com Grillo e Américo, desde a primeira edição brasileira da obra Marxismo e Filosofia da Linguagem (1979), o nome de Volóchinov sempre esteve associado ao de Bakhtin, de modo que uma boa parte dos

${ }^{1}$ Doutoranda Educação/Unicamp com graduação em Pedagogia pelo Instituto Social de Ciências Aplicadas (Isca Faculdades) e Mestrado em Educação/UNESP. Possui experiência em Educação Básica, Ensino Superior e principalmente com Formação Continuada de Professores.

${ }^{2} \mathrm{~A}$ expressão referida é dada ao grupo de estudiosos que se reuniam em torno do intelectual Bakhtin. Destacam-se: Medviédev, Maria Iúdina, Matvei Kagan, Lev Pumpianski e Ivan Solertinski, entre outros. (VOLÓCHINOV, 2019, p. 397).

(9) (1) Perspectivas em Diálogo, Naviraí, v. 8, n. 16, p. 349-352, jan./abr. 2021. 
pesquisadores brasileiros e russos costuma atribuir os textos à Mikhail Bakhtin e não a Volóchinov (p. 12). Nesse ínterim, outras duas edições russas foram publicadas de Marxismo e Filosofia da Linguagem (2017) ${ }^{1}$, com tradução das referidas pesquisadoras, porém, sem conceder autoria dos textos à Volóchinov.

Diante do exposto e na ausência de solução para a controvérsia autoral, a finalidade do presente estudo é apresentar um "esclarecimento baseado em dados factuais a respeito da atribuição dos textos de Valentin Nikoláeivitch Volóchinov [...]" (p. 12). Assim, nada mais contundente do que reunir em uma única obra textos inéditos de Volóchinov, bem como trazer à baila a tradução direta dos originais russos publicados entre 1919 - data de sua primeira publicação - e 1924 - ano que antecede o seu ingresso e a sua participação no renomado ILIAZV.

Consoante ao apresentado no texto introdutório, "a coleta foi acompanhada e orientada pelo trabalho na Filial de São Petersburgo do Arquivo da Academia Russa de Ciências [...]" (p. 7). As pesquisadoras fizeram uso em seu estudo de consulta "tanto da pasta pessoal de Volóchinov quanto das pastas de atividades gerais do Instituto" (p.11). Com relação à efetividade dos documentos analisados e traduzidos, Grillo e Américo indicam que, embora os textos sejam bastante reveladores e elucidativos, "o próprio material impossibilitou a construção de uma narrativa acabada sobre esse período da vida do autor uma vez que nos deparamos com lacunas e perguntas sem respostas, que mantivemos nas nossas conclusões" (p. 11).

Outro fato curioso acerca da vida de Volóchinov diz respeito a sua formação, posto que "os textos de jornal proporcionavam o contato com atividades de Volóchinov pouco conhecidas do leitor brasileiro: suas primeiras incursões na poesia e sua formação musical" (p. 9). Sobre o assunto, considerando o depoimento de "Bakhtin nas Conversas com Duvákin2" (1996), Volóchinov logo deixou de publicar poemas e concentrou-se em trabalhos como músico e compositor. De acordo com a pesquisa de Grillo e Américo, organizadoras da obra, na primeira fase de produção bibliográfica de Volóchinov (1919-1924), o autor utiliza-se de elementos essenciais que marcaram o seu processo de desenvolvimento histórico e social, posto que usufruiu de sua experiência em formação musical para acompanhar e avaliar a crítica musical da época, combinando-as aos conhecimentos de filosofia, estética e de sua experiência pessoal como compositor e pianista ( $p .9$ ). Além disso, o texto destaca que, na primeira fase da produção bibliográfica de Volóchinov, as pesquisadoras depararam-se com elementos de "rejeição à psicologização, preocupação com a metodologia, articulação entre as abordagens estética e histórica" (p. 9), ideias que posteriormente fizeram parte dos trabalhos do referido autor e de tantos outros integrantes do Círculo de Bakhtin, em especial, do próprio Bakhtin (p. 9).

No que tange à segunda fase de produção bibliográfica do autor em destaque, as obras já são conhecidas pelos leitores brasileiros, visto que foram publicadas em português ou mesmo em outras línguas românicas (entre elas, espanhol, francês e italiano). Estes textos foram produzidos após o ingresso de Volóchinov no ILIAZV e apresentados nos relatórios da pesquisa, uma vez que foram produzidos no período

${ }^{1}$ Cf. VOLÓCHINOV, Valentin. Marxismo de filosofia da linguagem: problemas fundamentais do método sociológico na ciência da linguagem. Tradução de Sheila Grillo e Ekaterina Vólkova Américo. São Paulo: Editora 34, 2017.

2 Destaques do autor. 
em que ele atuava como doutorando e pesquisador. Para tanto, a análise e a interpretação dos registros possibilitaram conferir para Volóchinov a autoria tanto dos textos originais que foram a base das traduções do russo para o português, quanto dos documentos consultados durante a pesquisa na Filial de Petersburgo do Arquivo da Academia Russa de Ciências (p. 10). Nas palavras de Grillo e Américo, "a pedra de toque da pesquisa" não é apresentar uma biografia retratada de Volóchinov e muito menos a ordem cronológica das obras de sua autoria. A proposta da pesquisa é reformular os acontecimentos a partir da coleta de informações dos registros originais, de modo a relacioná-los à atuação de Volóchinov no ILIAZV durante o período de 1924 a 1932, ou seja, a intenção das pesquisadoras é apresentar um retrato do período mencionado de sua vida acadêmica, de modo que este seja comprovado por meio dos registros disponíveis (p.12).

Outro fato destacado na obra como significativo para a pesquisa diz respeito aos estudos nos arquivos do ILIAZV, que forneceram um conhecimento maior do contexto ideológico e acadêmico e, talvez, o mais relevante do Círculo de Bakhtin, uma vez que "os artigos e livros assinados por Volóchinov fizeram parte dos relatórios de atividades apresentados no Instituto contribuindo para a elaboração do método sociológico na teoria literária e na linguística" (p. 12). Vale dizer também que, durante o desenvolvimento da pesquisa, em outros registros escritos por Volóchinov, foram identificados elementos teóricos muito difundidos pela teoria bakhtiniana, tais como a terminologia "arquitetônica", cuja autoria do termo é atribuída à Bakhtin ${ }^{1}$.

Contudo, a obra está organizada em um texto introdutório fruto da pesquisa realizada que revela os registros de Valentin Volóchinov presentes nos arquivos do ILIAZV, e segue com a coletânea de diversos outros textos inéditos e de outros já publicados, tais como ensaios, artigos, resenhas, poemas e uma breve biografia do autor supracitado e das pesquisadoras.

À guisa de conclusão, a obra é fruto de um trabalho laborioso, intenso e árduo sustentado por textos inéditos e outros já apresentados em outras ocasiões, consoante ao exposto em parágrafos anteriores. Não obstante, embora seja uma narrativa inacabada, considerando a ausência de respostas para muitas questões suscitadas pelas pesquisadoras durante o trabalho de investigação, a obra possibilita ao leitor reconstruir a biografia de Volóchinov, de modo a compreender melhor os aspectos relacionados ao contexto político, histórico, social e acadêmico do período. Trata-se de notável material destinado à pesquisadores e apreciadores da teoria da enunciação difundida pelo Círculo de Bakhtin.

\section{REFERÊNCIAS}

BAKHTIN, Mikhail Mikhailovich (VOLOCHINOV). Marxismo e filosofia da

linguagem. Problemas fundamentais do método sociológico na ciência da linguagem. Tradução de Michel Lahud e Yara Frateschi Vieira com a colaboração de Lúcia Teixeira Wisnik e Carlos Henrique D. Chagas Cruz. Prefácio Roman Jakobson. Apresentação Marina Yaguello. São Paulo: Hucitec, 1979.

${ }^{1} \mathrm{O}$ conceito aparece em artigo intitulado "O problema da Obra de Beethoven, partes I e II" e publicado por Volochinóv para designar a estrutura da obra musical (p. 09). 
VOLÓCHINOV, Valentin. A palavra na vida e a palavra na poesia: ensaios, artigos, resenhas e poemas. Organização, tradução, ensaio introdutório e notas: Sheila Grillo e Ekaterina Vólkova Américo. São Paulo: Editora 34, 2019.

VOLÓCHINOV, Valentin. Marxismo de filosofia da linguagem: problemas fundamentais do método sociológico na ciência da linguagem. Tradução de Sheila Grillo e Ekaterina Vólkova Américo. São Paulo: Editora 34, 2017. 